\title{
The unusual persistence of an ozone hole over a southern mid-latitude station during the Antarctic spring 2009: a multi-instrument study
}

\author{
E. A. Wolfram ${ }^{1}$, J. Salvador ${ }^{1}$, F. Orte ${ }^{1}$, R. D’Elia ${ }^{1}$, S. Godin-Beekmann ${ }^{2}$, J. Kuttippurath ${ }^{2}$, A. Pazmiño ${ }^{2}$, F. Goutail ${ }^{2}$, \\ C. Casiccia ${ }^{3}$, F. Zamorano ${ }^{3}$, N. Paes Leme ${ }^{4}$, and E. J. Quel ${ }^{1}$ \\ ${ }^{1}$ Centro de Investigaciones en Láseres y Aplicaciones, CEILAP-UNIDEF (MINDEF-CONICET), UMI-IFAECI-CNRS-3351, \\ UMI3351, Villa Martelli, Argentina \\ ${ }^{2}$ Laboratoire Atmosphère, Milieux, Observations Spatiales (LATMOS), Institut Pierre Simon Laplace, Université Pierre et \\ Marie Curie, Université Versailles St-Quentin-en-Yvelines, Centre National de la Recherche Scientifique, Paris, France \\ ${ }^{3}$ Laboratorio de Ciencias Atmosféricas, Universidad de Magallanes, PuntaArenas, Chile \\ ${ }^{4}$ Instituto Nacional de Pesquisas Espaciais, Brazil \\ Correspondence to: E. A. Wolfram (ewolfram@gmail.com)
}

Received: 6 February 2012 - Revised: 22 July 2012 - Accepted: 31 August 2012 - Published: 2 October 2012

\begin{abstract}
Record-low ozone column densities (with a minimum of 212 DU) persisted over three weeks at the Río Gallegos NDACC (Network for the Detection of Atmospheric Composition Change) station $\left(51.5^{\circ} \mathrm{S}, 69.3^{\circ} \mathrm{W}\right)$ in November 2009. Total ozone remained two standard deviations below the climatological mean for five consecutive days during this period. The statistical analysis of 30 years of satellite data from the Multi Sensor Reanalysis (MSR) database for Río Gallegos revealed that such a long-lasting low-ozone episode is a rare occurrence. The event is examined using height-resolved ozone lidar measurements at Río Gallegos, and observations from satellite and groundbased instruments. The computed relative difference between the measured total ozone and the climatological monthly mean shows reductions varying between 10 and $30 \%$ with an average decrease of $25 \%$. The mean absolute difference of total ozone column with respect to climatological monthly mean ozone column is around 75 DU. Extreme values of the UV index (UVI) were measured at the ground for this period, with the daily maximum UVI of around 13 on 15 and 28 November. The high-resolution MIMOSACHIM (Modélisation Isentrope du transport Méso-échelle de l'Ozone Stratosphérique par Advection) model was used to interpret the ozone depletion event. An ozone decrease of about 2 ppmv was observed in mid-November at the $550 \mathrm{~K}$ isentropic level ( $22 \mathrm{~km})$. The position of Río Gallegos rel-
\end{abstract}

ative to the polar vortex was classified using equivalent latitude maps. During the second week of November, the vortex was over the station at all isentropic levels, but after 20 November and until the end of the month, only the 10 lower levels in the stratosphere were affected by vortex overpasses with ozone poor air masses. A rapid recovery of the ozone column density was observed later, due to an ozone rich filament moving over Río Gallegos between 18 and $24 \mathrm{~km}$ in the first two weeks of December 2009.

Keywords. Atmospheric composition and structure (Middle atmosphere - composition and chemistry)

\section{Introduction}

The Antarctic ozone hole is one of the most important perturbations that human activities have provoked in our atmosphere (WMO Report, 2007). The ozone hole started to develop each spring in the southern polar region in the early 1980s. Most recent studies point out that the detection of a statistically significant decrease in its area will not occur before about 2020 (Newman et al., 2006).

In the course of the past twenty years, this phenomenon has varied in size and minimum total ozone value. During spring, stratospheric dynamical processes cause changes in the size and shape of the polar vortex and sometimes it 
elongates towards lower latitudes. The daily movement of the vortex combined with this particular shape induces overpasses of the ozone hole over the continental part of South America. In these situations large inhabitant cities like Punta Arenas (119496 inhabitants), Río Gallegos (79 144 inhabitants), and Ushuaia (56 825 inhabitants) are under the influence of the ozone hole or near its border, causing an increase of solar UV radiation at these locations (Pazmiño et al., 2005; Wolfram et al., 2008).

Recent studies have shown that while the first stage in ozone recovery (ozone stabilization at global scale) has been reached in the first decade of the 21st century (Newman et al., 2004; Yang et al., 2005), the second stage of recovery (statistically significant upward trend after removal of all other known influences such as solar cycle and volcanic aerosols) will not be detected until about 2020, due to the slow decrease in the concentration of ozone depletion substances (ODS) in the polar stratosphere (Newman et al., 2006). However, there is a great deal of uncertainty linked to climate change and its impact on the ozone hole, depending on the evolution of the stability of the Antarctic polar vortex. Despite the fact climate change is expected to accelerate the ozone recovery and the disappearance of the ozone hole (WMO, 2011), most climate models predict an increase in the dynamical activity in the Southern Hemisphere due to the increase in the "forcing" of planetary waves generated in the troposphere (Austin et al., 2010), which will affect the stability of the Antarctic polar vortex and lead to excursions of poor ozone air masses over populated regions of the Southern Hemisphere and more specifically the southern part of South America during the springtime (Eyring et al., 2010). The study of the effect of such excursions on surface UV radiation in present conditions is thus of interest in this context.

The analysis of historical ground-based total ozone observations in October show that the depletion started in the late 1970s in the Antarctic region, reached a maximum in the early 1990s, and stabilised afterwards due to saturation (WMO, 2007, and references therein). There is no indication of ozone recovery yet (second stage). At southern midlatitudes, a focus region in this paper, a reduction of 20-50\% is observed for a few days in October-November at Río Gallegos site (Kuttippurath et al., 2010b).

Using measurements from ground stations and from satellites instruments, a recent study found that the ozone hole was centered just off the southern tip of Argentina and Chile for three weeks in November 2009, in contrast with its usual climatogical position centered over Antarctica. Analysis of 30 years of assimilated total $\mathrm{O}_{3}$ column and UV index measurements shows that this 20-day event was unique in the history of the ozone hole for these latitudes (de Laat et al., 2010).

The objective of this paper is to make a multi-instrument study of this unique event by the use of different groundbased instruments operating at the CEILAP Río Gallegos site (hereafter CEILAP-RG), focusing on ozone profiles mea- sured by the NDACC (Network for the Detection of Atmospheric Composition Change) ozone differential absorption lidar (DIAL). The impact of the ozone hole passing over Río Gallegos during this extreme event is quantified by the comparison of lidar ozone profiles measured during November 2009 in the CEILAP-RG site and climatological ozone profiles. Complementary measurements of total ozone column by different ground- and satellite-based instruments and solar UV index are also reported in this paper for a better analysis of this unique event. The high-resolution chemistrytransport MIMOSA-CHIM model is used to quantify the ozone depletion.

This paper is organized as follows: First, the CEILAP-RG site instrument capabilities are presented followed by a description of the method used in this paper to detect vortex occurrence over Río Gallegos at four isentropic levels. In Sect. 4, the total ozone and ozone profiles temporal evolution at Río Gallegos are shown and compared with climatological ozone profile and model calculation. Complementary measurements of surface UV irradiances are included in order to evaluate the impact of this event on UV radiation reaching the ground. Finally, a discussion of this extreme event is given.

\section{CEILAP-RG site description: instrument capabilities}

The CEILAP-RG site is part of the Lidar Division of CEILAP in South Patagonia. Since June 2005, a shelter with several lidar instruments developed in collaboration with LATMOS (CNRS) was deployed in this Patagonian city, $2600 \mathrm{~km}$ from Buenos Aires. During 2005 and 2007, with the financial support of JICA (Japan International Cooperation Agency), the SOLAR Campaign was held (www. division-lidar.com.ar) (Wolfram et al., 2006). The principal objective of this campaign was to study the ozone layer when the polar vortex overpassed the continental part of Argentina, in South America.

After the SOLAR campaign, different projects were developed with financial support of JICA in partnership with researchers from France, Japan and Chile. The main objectives of these projects are the measurement of various atmospheric parameters and stratospheric ozone profiles using lidar remote sensing techniques. Río Gallegos is located at southern subpolar latitudes, making it a very interesting place to observe the perturbations that the ozone hole induces on midlatitude ozone vertical distribution. The only ground-based lidar experiments carried on in southern Latin America to observe the ozone profile are made in the CEILAP-RG station. The activity of this site permits monitoring of the evolution of ozone vertical distribution in the $12-45 \mathrm{~km}$ altitude range during the year. Beyond satellite profiles, ozone sondes are launched in Punta Arenas (Chile) and Ushuaia (Argentina).

In addition to lidar measurements, other available instruments at the CEILAP-RG site are used for a thorough study 
Table 1. List of instruments considered in this study.

\begin{tabular}{lll}
\hline Instrument & Product/type of measur. & Institution/country \\
\hline DIAL & Ozone vertical profile/ground-based & CEILAP/Argentina \\
GUV 541 & UV index/ground-based & CEILAP/Argentina \\
ECC sonde & Ozone vertical profiles/in situ & UMAG/Chile \\
Brewer SN 124 & Total ozone/ground-based & INPE/Brazil \\
Brewer SN 180 & Total ozone/ground-based & UMAG/Chile \\
SAOZ & Total ozone/ground-based & UVSQ/France \\
OMI & Total ozone/satellite & NASA/USA \\
\hline
\end{tabular}

of the unusual event investigated in this paper. Table 1 shows the list of observations used to diagnose the atmospheric phenomenon.

\subsection{Differential Absorption Lidar (DIAL)}

The instrument developed at the CEILAP laboratory is an improved version of the previous one (Pazmiño, et al., 2001). The new setup was developed in collaboration with LATMOS, and the optical receiving system is similar to that developed for other lidar systems, such as the instrument at Observatoire de Haute-Provence, France (OHP) (GodinBeekmann et al., 2003). The DIAL technique requires two emitted wavelengths that in this instrument are generated by two emitter lasers: an excimer $(\mathrm{XeCl})$ laser emitting at $308 \mathrm{~nm}$ with $30 \mathrm{~Hz}$ repetition rate, and maximum energy per pulse of $300 \mathrm{~mJ}$ is used for the wavelength absorbed by ozone. The reference wavelength corresponds to the third harmonic of a Nd-YAG laser emission, at $355 \mathrm{~nm}, 30 \mathrm{~Hz}$ repetition rate and $130 \mathrm{~mJ}$ maximum energy.

The optical receiver of the DIAL instrument that collects the backscattered photons is made up of four Newtonian (f/2) telescopes. Each of them has a $50 \mathrm{~cm}$ diameter with parabolic aluminized surfaces of $48 \mathrm{~cm}$ diameter. This produces a total reception area of $\sim 7238 \mathrm{~cm}^{2}$. At the focus of each telescope, an optical fiber of $0.94 \mathrm{~mm}$ effective diameter, $0.22 \pm 0.02 \mathrm{nu}-$ merical aperture, and $0.27 \mathrm{db} \mathrm{km}^{-1}$ attenuation (at $308 \mathrm{~nm}$ ) is placed. The other end of the fiber is positioned at the focus of a quartz lens placed inside a spectrometer used for the separation of the received wavelengths. A mechanical chopper is positioned at the entrance of the spectrometer. It has a rotating frequency of $300 \mathrm{~Hz}(18000 \mathrm{rpm})$, and its role is to block the strong lidar signals originated from the lower part of the atmosphere. The full description of the DIAL instrument and the intercomparison with independent ozone measurements can be found in Wolfram et al. (2008).

The ozone number density is computed from the difference of the slopes of the signals originated from Rayleigh scattering of the emitted laser beams. Since lidar signal covers a very large dynamical range, they have to be attenuated for the measurements in the lower stratosphere. The final ozone profile measurement corresponds thus to a composite profile computed from the "low" and "high" energy Rayleigh signals which are detected simultaneously.

A typical experiment lasts 3-4h, leading to a horizontal spatial resolution of $100-200 \mathrm{~km}$. The vertical resolution ranges from $0.7 \mathrm{~km}$ at $14 \mathrm{~km}$ to $4 \mathrm{~km}$ at $35 \mathrm{~km}$, with a corresponding total uncertainty varying from 3 to $15 \%$ in the same altitude range. This instrument contributes to NDACC and is one of only five instruments of this type in the Southern Hemisphere. The standard number of experiments per year is around 40 with a seasonal distribution that has a maximum rate during austral spring, coincident with the development of the ozone hole.

\subsection{Ground-based passive sensors}

\subsubsection{System d'Analyse par Observation: SAOZ}

The zenith sky SAOZ UV-VIS spectrometer (Pommereau and Goutail, 1988) belonging to LATMOS operates at 300$650 \mathrm{~nm}$, looking at sunlight scattered from the zenith sky during twilight. Ozone is measured at high solar zenith angles (SZA) between $86^{\circ}$ and $91^{\circ}$ every morning and evening in the Chappuis band (450-650 nm). Various inter-comparison exercises concluded that the measurements from different SAOZ instruments are consistent within $\pm 3 \%$ (Roscoe et al., 1999; Vaughan et al., 1997). The SAOZ spectrometer at CEILAP-RG site was installed in March 2008, and it measures ozone and nitrous dioxide columns twice a day, at sunrise and sunset. This instrument is also part of NDACC network. The SAOZ data used in this paper are the consolidated data Version 2 (V2) (Hendrick et al., 2011).

\subsubsection{GUV radiometer}

Real-time UV and ozone data are derived from measurements of multi-channel moderate-bandwidth GUV filter radiometers, designed and manufactured by Biospherical Instruments Inc. The instruments provide measurements in five approximately 10-nm-wide UV bands centered at 305, 313, 320,340 , and $380 \mathrm{~nm}$. The angular response of the radiometer's collector has virtually no azimuth dependence, and its cosine error is smaller than $\pm 3 \%( \pm 7.5 \%)$ for zenith angles less than $65^{\circ}\left(82^{\circ}\right)$. The instrument and its data have been 
described in several publications (Dahlback, 1996; Booth et al., 1994; Fuenzalida et al., 1998). This instrument integrates the Solar Monitoring Network Argentina (Orce et al., 1998), and since June 2005 it was installed at CEILAPRG. The multi-channel moderate-bandwidth GUV-541 has proven to be an acceptable solution for this type of monitoring. It is a good alternative to UV spectroradiometers, which are very expensive and maintenance intensive, and broadband radiometers that provide limited information because they cannot distinguish between changes in UV radiation caused by variation in cloud cover and changes caused by variation in ozone amount.

\subsubsection{Brewer spectrophotometer}

Brewer spectraphotometers are ones of more sophisticated instruments to take measurements of total ozone column in an automatic way. Its measurements also make use of differential absorption in the UV region (Brewer, 1973) for the determination of total ozone, similar to that of the Dobson, but sensitivity of the Brewer instrument is better. An empirical relation between simultaneous direct sun and zenith sky has to be established if zenith observations are to be taken. Calibration of the instrument is essential. The Brewer installed in CEILAP-RG site is a Mark IV single monocromator (SN 124), and it was installed in November 2008. It belongs to INPE/Brazil. A second Brewer instrument was taken into consideration in this study from Laboratorio de Ozono y RUV of Magallanes University, Punta Arenas, Chile. It is a Mark III double monocromator (SN 180).

\subsection{Satellite measurement}

The satellite measurements considered in this work are the total ozone column from Ozone Measurement Instrument (OMI) and the Multi Sensor Reanalysis (MSR) data. The OMI sensor on the Aura satellite is a successor to the Total Ozone Mapping Spectrometer (TOMS), and it began to operate in 2004 (Levelt et al., 2006). The measurements of this instrument are made by an UV-VIS spectrometer in nadir view. It measures solar light scattered photons by the atmosphere with a spatial resolution at nadir of $13 \times 24 \mathrm{~km}$. The overpass data, spatial averages within $100 \mathrm{~km}$, are retrieved using the TOMS $\mathrm{v} 8$ algorithm. The uncertainty of the ozone column is $2-5 \%$ for $\mathrm{SZA}<84$.

In addition, we use daily total $\mathrm{O}_{3}$ columns obtained from the Multi Sensor Reanalysis (MSR) project, which produced a 30-year total $\mathrm{O}_{3}$ column assimilation dataset for 1979-2008. These data are based on a total of eleven satellite instruments measuring total $\mathrm{O}_{3}$ columns - including SCIAMACHY - that were operating during various periods within these 30 years (van der A et al., 2010). The daily and monthly climatological values of total ozone and UV index for Río Gallegos were calculated with the online sources dataset summarized as daily MSR total ozone columns at 12:00 UTC, http://www.temis.nl/protocols/ o3field/o3field_msr.php; daily MSR maximum UVI data, http://www.temis.nl/uvradiation/MSR/uvief.php. The period 1979-2008 was chosen for the climatology. From 1989 onwards the large $\mathrm{O}_{3}$ holes occurred, and $\mathrm{O}_{3}$ depletion was more or less constant (WMO, 2007).

\subsection{Ozone sonde measurement}

The Laboratory of Monitoring of Ozone and UVR (LabO3RUV) of the University of Magallanes (UMAG) at Punta Arenas, Chile $\left(53^{\circ} \mathrm{S}, 70.9^{\circ} \mathrm{W}\right)$ have been performing regular ozone soundings from September 2009. Soundings have been carried out twice a month and daily during the activity of the Antarctic Ozone Hole over Punta Arenas. A Lockheed Martin LMG6 ground system unit, LMS6 meteorological radiosonde and electrochemical concentration cell (ECC) ozonesondes from EN-SCI Corporation have been used. A $1 \%$ solution of KI was used. The ozone sensor of the ECC ozonesonde is an iodine/iodide redox concentration cell composed of two platinum electrodes immersed in neutral buffered iodide solutions of different concentration in the anode and cathode chambers. An electric current is generated when air containing ozone is pumped into the cathode. Both ECC and LMS6 are carried aloft on balloons from the ground to the burst altitude of the ballon, normally near $28-30 \mathrm{~km}$. Between LabO3RUV-UMAG and CEILAP an agreement exists to compare ozone profiles obtained with DIAL and ECC in the Patagonia under the $\mathrm{UVO}_{3}$ Patagonia (Argentina-Chile) project carried on between 2007-2011.

\section{Classification method: equivalent latitude}

The position of Río Gallegos with respect to the vortex is evaluated in the 2-D quasi-conservative coordinate system (equivalent latitude/potential temperature) described by McIntyre and Palmer (1984). This methodology was previously used for the evaluation of ozone loss rates in spring at the Antarctic station of Dumont d'Urville (Godin et al., 2001) and in the studies of impact of polar vortex on ozone and ultraviolet B radiation in south Argentina (Pazmiño et al., 2005). In our study, this methodology permits us to find the occurrence of polar ozone depleted air masses over the measurement site. The meteorological data from the European Center for Median Range Weather Forecasts (ECMWF) analyses $\left(2.5^{\circ} \times 2.5^{\circ}\right)$ are used to compute the equivalent latitude (EL) and potential temperature. The EL is a modified potential vorticity (PV) variable defined as the latitude enclosing the same area as the corresponding PV contour. In this new coordinate system, the pole corresponds to the position of maximum PV. Following the evolution of PV as a function of EL, three regions can be distinguished: inside the vortex, characterized by high PV values; the vortex edge, corresponding to the high PV gradient area; and outside the 
vortex, with small PV values. The vortex edge is very weakly mixed due to high PV gradient. In contrast, the PV gradient is low inside the vortex (i.e. vortex core) and outside the vortex, and therefore they are strongly mixed regions (Lee et al., 2001).

The position of the vortex limit and its boundaries are calculated every day from the middle of September to December covering the study period in 2009 , using the method of Nash et al. (1996). In this methodology the vortex limit corresponds to the EL where the gradient of PV weighted by the wind module is maximum. The local extreme of the second derivative corresponds to the inner and outer boundaries. Finally, to smooth the variability that is produced by the calculation, the limit and borders of the vortex are smoothed temporally with a moving average of five days.

The polar vortex starts to develop at the beginning of the winter in the upper stratosphere, and it usually persists until late November to late December depending on the altitude. The vortex makes a dynamical barrier that results in a strong temperature gradient between polar and mid-latitudes regions. It grows in size and develops downward. With the return of sunlight, the vortex is deformed by the increasing planetary wave activity, which produces changes in the shape and position of it. It starts to break earlier in the upper stratosphere until the final stratospheric warming. These deformations are important to take into account because they occur in late November and early December when the solar elevation is large. The combination of polar air masses with low ozone concentration and high solar elevations may result in high UV levels.

The ozone loss by the passive method is computed by subtracting passive ozone (ozone calculated without interactive chemistry) from lidar ozone measured (Kuttippurath et al., 2010a). This approach separates the contribution due to transport and photochemical loss in total ozone evolution during the winter. The tracer calculations are performed by chemical transport models (CTMs) in which photochemistry is deactivated to represent the dynamical evolution of the ozone during the winter. The Modèle Isentrope du transport Mésoèchelle de l'Ozone Stratosphérique par Advection (MIMOSA) was used to capture and quantify the filamentary structures passing over Europe in winter and spring to assess the importance of such structures in the irreversible transport of polar air into mid-latitudes. It was originally developed at LATMOS and a full description of MIMOSA is given by Hauchecorne et al. (2002). The potential vorticity (PV) is advected isentropically with a 1-h elementary time step and re-interpolated onto a regular longitudelatitude fine grid. Sensitivity studies of this CTM model have shown that uncertainties in advection lead to fine structure position errors not exceeding $200 \mathrm{~km}$ (Hauchecorne et al., 2002). The MIMOSA-CHIM is the chemistry extended version of the model, and combines the PV advection scheme and the chemistry scheme of the model REPROBUS (Reac-

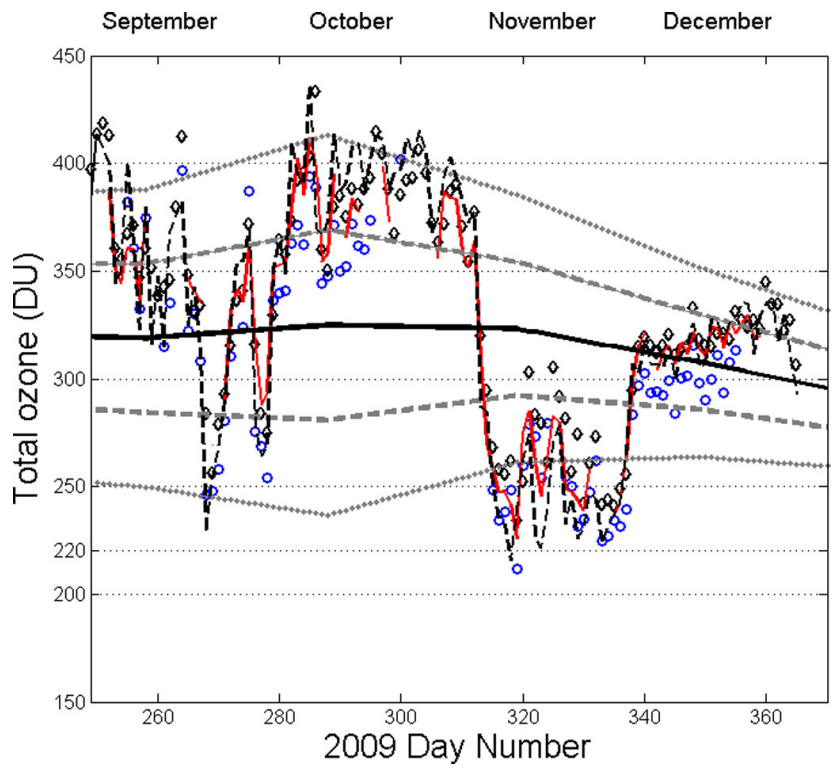

Fig. 1. 2009 daily evolution of total ozone column at Río Gallegos measured with Brewer 124 spectrophotometer (blue open circles), SAOZ spectrometer (black open diamonds), and OMI satellite measurements (red line). The $\mathrm{SAOZ}$ data corresponds to mean sunrise and sunset values. Total ozone column at Punta Arenas measured with Brewer SN 180 is shown as a dashed black line. Data span from the middle of September to the end of December. Climatological MSR monthly mean total ozone column for Río Gallegos site (1978-2008) (black solid line) \pm 1 SD (dashed gray lines) and $\pm 2 \mathrm{SD}$ (dotted gray line) are also shown.

tive Processes Ruling the Ozone Budget in the Stratosphere) (Lefèvre et al., 1994; Tripathi et al., 2006).

\section{Results}

\subsection{Total ozone measurements}

In this section we analyze the time evolution of total ozone column for the 2009 spring season, paying special attention to November. Since the discovery of the ozone hole in Antarctica, the southern parts of South America have usually been affected by frequent overpasses of the polar vortex. The vortex stretches and becomes more elliptic frequently while it rotates over the Antarctic continent with an average period of about 20 days. Figure 1 shows the daily evolution of the total ozone column for Río Gallegos site measured by satellite and ground-based instruments described in Sect. 2. The climatological mean from the MSR time series is also represented in this figure together with the 1st and 2nd standard deviations (SDs). The time period reported in this figure spans from September to December 2009. Note that at the end of September and beginning of October (day of year: 263-283), the edge of the Antarctic vortex passed over the Río Gallegos region twice, which resulted in small $\mathrm{O}_{3}$ 


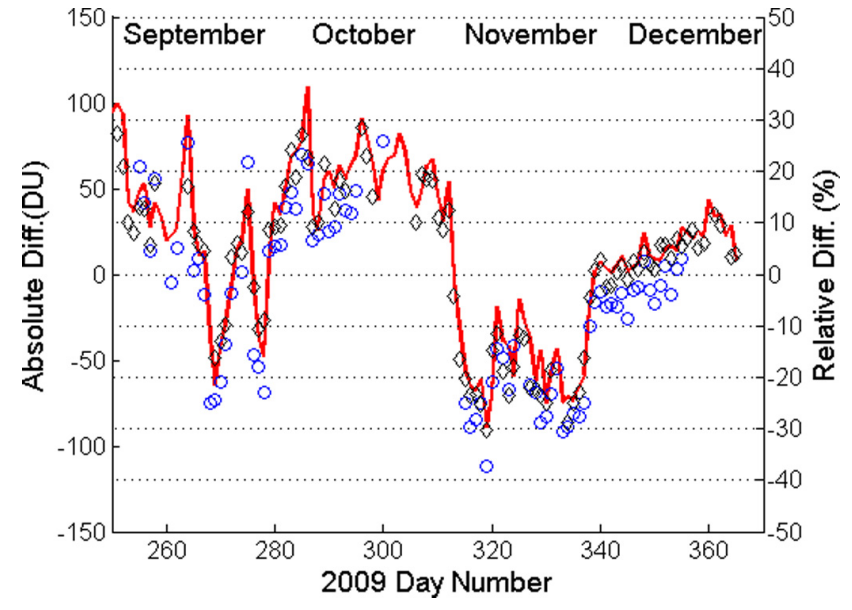

Fig. 2. Differences (absolutes and relatives) of 2009 daily total ozone column with respect to climatological total ozone column for Río Gallegos. Differences with respect to Brewer MkIV spectrometer (blue circles) and SAOZ spectrometer (black open diamonds), and OMI satellite measurements (red line) with respect to climatological monthly mean. The SAOZ data corresponds to mean sunrise and sunset values. Data span from the middle of September to the end of December. Absolute differences are calculated as instruments (inst) less climatology (clim) (left axis), and relative differences are calculated as (inst $-\mathrm{clim}) / \mathrm{clim} \times 100$ (right axis).

columns and enhanced UVI values. The total ozone columns corresponding to these days are around $250 \mathrm{DU}$, but these events are inside the two standard deviations (SDs) of the climatological mean and will not be considered in this study. We focused on November (day number 305 to 334), when remarkably low total ozone columns were registered by the different instruments involved in this study. This extreme event was beyond two standard deviation of the 30-year November climatological mean. The large decrease in ozone columns (and corresponding high UVI shown in Sect. 5) around 15 November 2009 are easily identified. The mean absolute difference of total ozone column with respect to climatological monthly mean ozone column is $62.2 \mathrm{DU}$ for this 20-day period and 32.9 DU for the complete month of November (Fig. 2, left vertical axes). The minimum ozone column of this extreme event occurred on 15 November (day number 319) with 212 DU measured by Brewer (SN 124), $226 \mathrm{DU}$ measured by SAOZ and 234 DU observed by OMI. The relative differences between instrument measurements (inst) and climatological monthly mean (clim) total ozone were calculated as $100 \times($ inst - clim $) / c l i m$. The relative differences range around -10 to $-30 \%$, with a mean reduction of $25 \%$ (Fig. 2, right vertical axes). The total ozone column satellite map on November 15 showed the ozone hole elongated elliptically over the southern part of South America, covering the position of the Río Gallegos site.

These low total ozone column values are not unusual for this latitude, as revealed by the MSR data, but the unusual
Table 2. Statistical analysis of MSR database overpasses at Río Gallegos.

\begin{tabular}{cc}
\hline $\begin{array}{c}\text { Occurrence number of } \\
\text { consecutive days }\end{array}$ & $\begin{array}{c}\text { Frequency of } \\
\text { occurrence }(\%)\end{array}$ \\
\hline 1 & 59.5 \\
2 & 26.9 \\
3 & 10.2 \\
4 or more & 3.3 \\
\hline
\end{tabular}

situation is the prolonged persistence of low total ozone columns over this site due to the vortex overpasses during 20 consecutive days in November. De Laat et al. (2010) showed from the analysis for MSR that a 20-day period with total ozone columns outside the $95 \%$ confidence interval and UVI values larger than 10 for up to 18 days never occurred for the period 1979-2008 at any longitude for the latitudes during the latter two decades between $52^{\circ} \mathrm{S}$ and $56^{\circ} \mathrm{S}$ during November.

To show how unusual this event was at Río Gallegos, we made a statistical analysis of 30-year MSR data for the CEILAP-RG site. In this study we considered that one day with total ozone column below two standard deviations (SDs) of the daily climatological mean as a day with statistical ozone depletion. The second criterion for the statistical analysis was to compute the number of statistical ozone depletion events occurring in a consecutive way. The analysis reveals that days with total ozone column below 2 SDs of the climatological daily mean are distributed as follows: Around $60 \%$ of cases correspond to events of only one day, with the day after the event showing a quick increase in the total ozone column out of the threshold of 2 SDs below the climatological mean. In second place of occurrence there are the events with two consecutive days of lower ozone with $27 \%$ of occurrences. $10 \%$ of events correspond to three consecutive days below $2 \mathrm{SDs}$ of the climatological mean, and only $3 \%$ of the cases of total ozone column below 2 SDs of climatological daily mean correspond to four or more consecutive days (Table 2). The analysis of these extreme cases shows that this small percentage corresponds to the years 1994, 2002 and 2009. In 1994, an event of 5 consecutive days of extreme ozone depletion (beyond 2SD) occurred in October and not in November as the case in study here, while in 2002, the sudden stratospheric warming split the vortex in two parts (Feng et al., 2005; Roscoe et al., 2005) and ozone poor filaments moved into the mid-latitudes and produced six days with low ozone over Río Gallegos. The event of November 2009 studied in this paper was unique in the history of the ozone hole in the mid-latitudes as the total ozone was below $2 \mathrm{Sds}$ of the climatological mean during 5 consecutive days in November, as analyzed from the 30-year data at Río Gallegos. 
Table 3. Lidar measurements considered in this study.

\begin{tabular}{cccccc}
\hline $\begin{array}{c}\text { Measurement } \\
\text { number }\end{array}$ & $\begin{array}{c}\text { Date } \\
\text { dd/mm/yyyy }\end{array}$ & $\begin{array}{c}\text { Day } \\
\text { number }\end{array}$ & $\begin{array}{c}\text { Start time } \\
\text { (UTC) }\end{array}$ & $\begin{array}{c}\text { Stop time } \\
\text { (UTC) }\end{array}$ & $\begin{array}{c}\text { Integration time } \\
\text { (Hs) }\end{array}$ \\
\hline 1 & $01 / 11 / 2009$ & 305 & $0: 50$ & $03: 50$ & $03: 00$ \\
2 & $05 / 11 / 2009$ & 309 & $02: 15$ & $04: 45$ & $02: 30$ \\
3 & $09 / 11 / 2009$ & 313 & $02: 05$ & $04: 52$ & $02: 47$ \\
4 & $13 / 11 / 2009$ & 317 & $05: 05$ & $08: 00$ & $02: 55$ \\
5 & $14 / 11 / 2009$ & 318 & $02: 00$ & $07: 08$ & $05: 08$ \\
6 & $23 / 11 / 2009$ & 327 & $01: 15$ & $06: 23$ & $05: 08$ \\
7 & $24 / 11 / 2009$ & 328 & $02: 45$ & $06: 57$ & $04: 12$ \\
8 & $08 / 12 / 2009$ & 342 & $03: 35$ & $06: 48$ & $03: 13$ \\
9 & $13 / 12 / 2009$ & 347 & $02: 34$ & $07: 06$ & $04: 32$ \\
\hline
\end{tabular}

\subsection{Lidar ozone profiles}

Height-resolved ozone measurements over Río Gallegos were measured with a differential absorption lidar (DIAL) instrument. A total of nine lidar profiles were selected for this study, in which seven of them were observed in November. Table 3 summarizes the details of each experiment considered in the present work. Commonly, the lidar measurements carried out in November 2009 have a duration that ranges from 3-5h. Longer experiments are not possible at the CEILAP-RG site due to cloud cover and night duration. The cloud cover is very high in Patagonia region and has a seasonal cycle that maximizes in summer. This situation together with the length of nights makes it difficult to perform lidar measurements in CEILAP-RG at this time of the year.

The ozone number densities as a function of altitude for selected days are shown in Fig. 3. The dynamic range covered for the measurements is 14.5 to $45 \mathrm{~km}$. To quantify the reduction and change in the shape of the ozone vertical profile, the November ozone climatology profile (Fortuin and Kelder, 1998) is included in Fig. 3 for the latitude band $45^{\circ}-$ $55^{\circ} \mathrm{S}$. The climatology in mixing ratios was made from several satellite and ozonesonde observations during the 19801991 period and is available for 17 latitudinal bands from -80 to 80 degrees spacing at 17 pressure levels between 100 and $1 \mathrm{hPa}$. These climatological profiles are converted to number density profiles using the CIRA temperature data for the respective latitude and altitude levels (COSPAR, 2006).

We observe three different deviations from the climatological profile: The first three profiles (1, 5 and 9 November) show an increase in the ozone number density below $20 \mathrm{~km}$ height; the second two lidar profiles (13 and 14 November) show the loss in ozone at all altitudes, the measurement on 13 November in particular. By the end of the month, the reduction is visible below $26 \mathrm{~km}$. The two lidar profiles of December have been included to show the recovery to near normal ozone profiles after the pass of this extreme event. However, the lidar profiles in December show a small perturbation around $25 \mathrm{~km}$, due to the vortex dilution process.

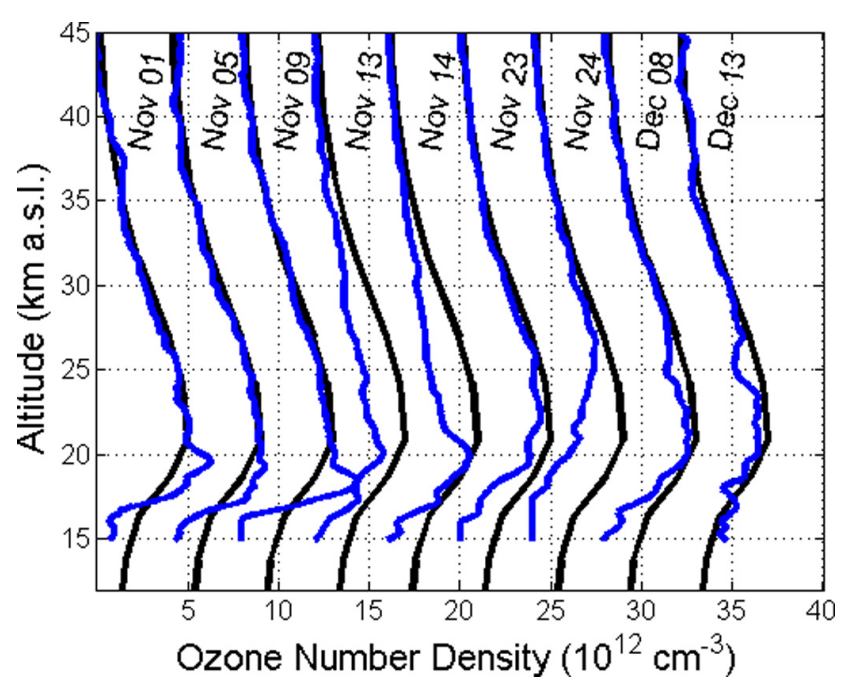

Fig. 3. Lidar ozone profiles measured in Río Gallegos sites (blue lines) from 1 November to 13 December 2009. The details of lidar experiments are listed in Table 2. For comparison of vertical ozone profile shape change, the November climatological Fortuin and Kelder ozone profile is included (black lines). The profiles have been offset successively by $4 \times 10^{12} \mathrm{~cm}^{-3}$.

With the aim to show the variability of ozone concentration over Río Gallegos in this time period, we made a timeheight 2-D cross section of ozone number density profiles (Fig. 4, left side). To show the impact of polar vortex overpass in Río Gallegos during this extreme event, we calculate the anomaly profile defined as subtraction of each single profile from the November climatological mean (Fig. 4, right panel). We can observe the impact of ozone hole overpass on 13 and 14 November profiles, where the reduction in ozone is observed at the full range covered by the lidar measurement. The absolute differences shows a maximum of about $3 \times 10^{12}$ molecules $\mathrm{cm}^{-3}$ around $25 \mathrm{~km}$. It should be mentioned that some of the patterns seen in Fig. 4 can be caused by the software used to perform these graphics and its interpolation scheme. 

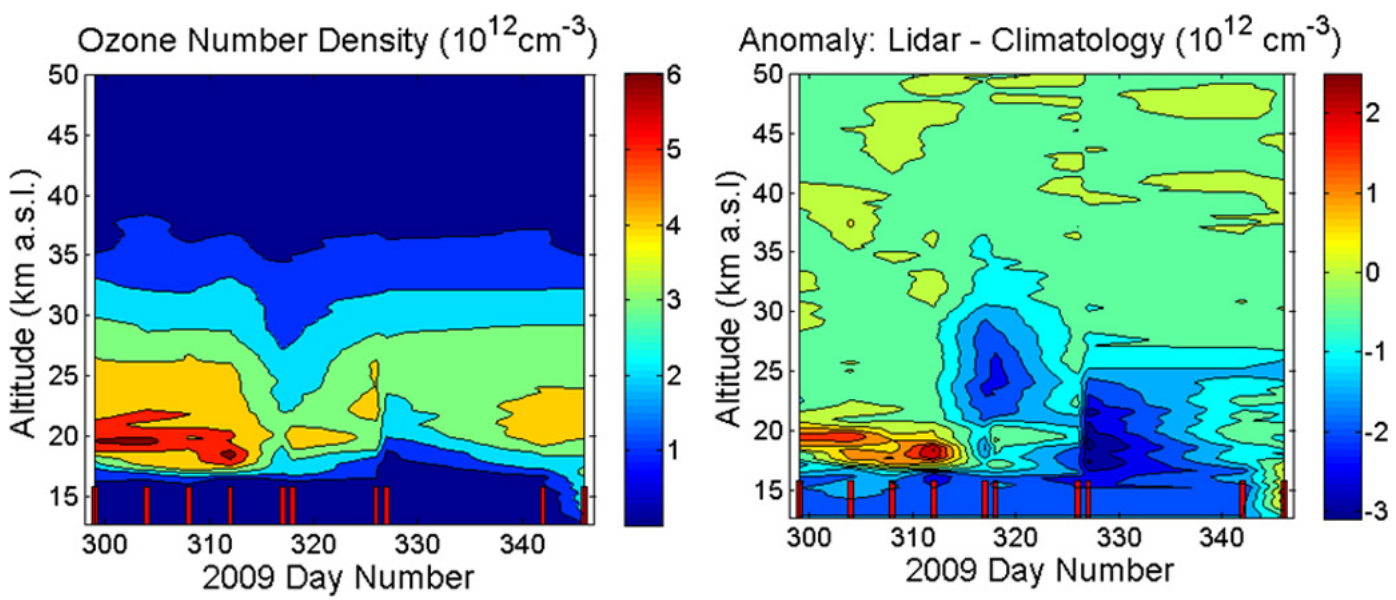

Fig. 4. 2-D time-altitude cross section of lidar ozone number density for the CEILAP-RG site (left panel). 2-D time-altitude cross section of number density anomaly (lidar-climatological profile) (right panel). Vertical red bars indicate the lidar measurements.

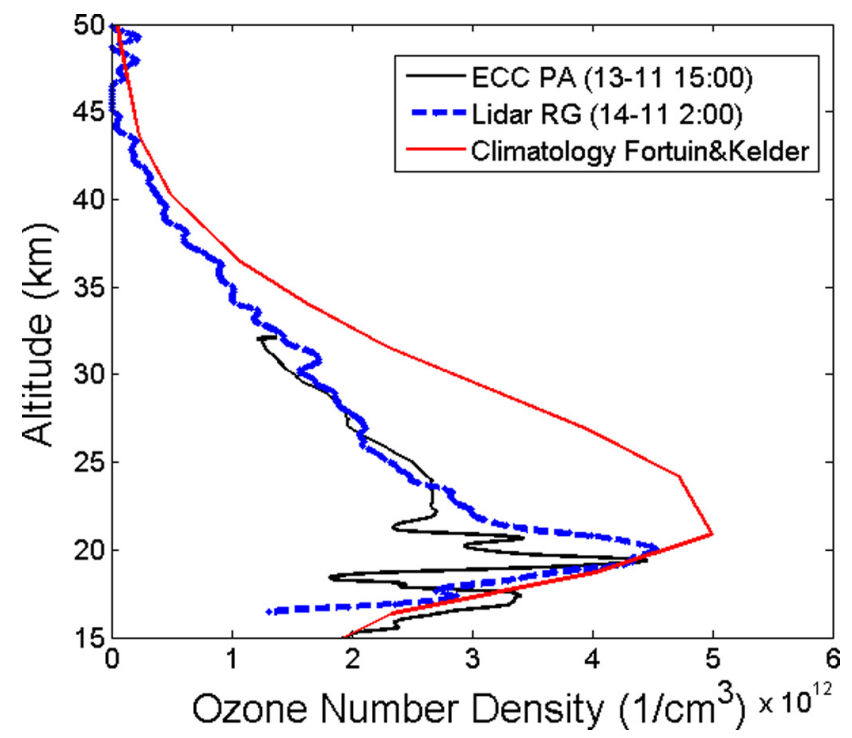

Fig. 5. Intercomparison of lidar ozone profile on 14 November 2009 (start time 02:00 UTC) measured at Río Gallegos (blue dashed line) and ECC ozonesonde launched on 13 November (15:00 UTC) in Punta Arenas, Chile (black line). Fortuin and Kelder climatological profile for $45^{\circ}-55^{\circ}$ latitude south band is also plotted as a reference (red line).

In this paper, we include the ECC ozonesonde profile launched in Punta Arenas on 13 November (15:00 UTC) as additional information. Figure 5 shows the ECC profile taken on 13 November and lidar profile measured the night after that (14 November, 02:00 UTC). Both profiles show strong reduction with respect the Fortuin and Kelder climatology, mainly above $20 \mathrm{~km}$. In general, the agreement between both types of measurements is good, showing the influence of polar vortex intrusion over southern South America, but the vertical resolution of lidar did not permit catching the laminate shape of the ozone profile linked to the presence of the polar vortex.

\subsection{Solar UV radiation measurement}

As it is well known, there is an anticorrelation between total ozone content and solar UV crossing the atmosphere (Booth and Madronich, 1994). In addition to ozone, aerosols, cloud cover and solar position affect the solar UV levels that reach ground. In Río Gallegos, the aerosol load is very low and does not affect the UV radiation. In the period studied here, the passage of ozone poor airmasses over Río Gallegos caused elevated values of solar UV radiation at the ground. Figure 6 shows the total ozone column (upper panel) together with the maximum daily value of UV index (UVI) (lower panel). The plots span from August to the end of December 2009 and clearly show the anticorrelation between ozone and UV during November extreme events. The climatological daily means of the UV index reported here were calculated with the GUV database records from 2005 to 2008. The shaded area corresponds to $\pm 1 \mathrm{SD}$ of the daily mean.

The increasing trend in the daily mean UV level with time is due to increase in solar elevations. In addition, the daily maximum UVI is modulated by total ozone content and cloud cover. The maximum UVI (UVI =13) was reached on 15 November 2009, but in the whole 20-day period studied here, high values of UV index were registered. Daily maximum UVIs reported in Fig. 6 are classified in different colors according to the color code suggested by the World Health Organization (WHO, 2002) for the dissemination of the UVI to the public. Low UVI are plotted in green, moderate in yellow, high in orange, very high in red and extreme UVI in violet. We note that maximum UVI for the 20-day period of November covered in this study reached extreme values.

The time evolution of UVI for selected days in November is presented in Fig. 7. The measurements were performed 


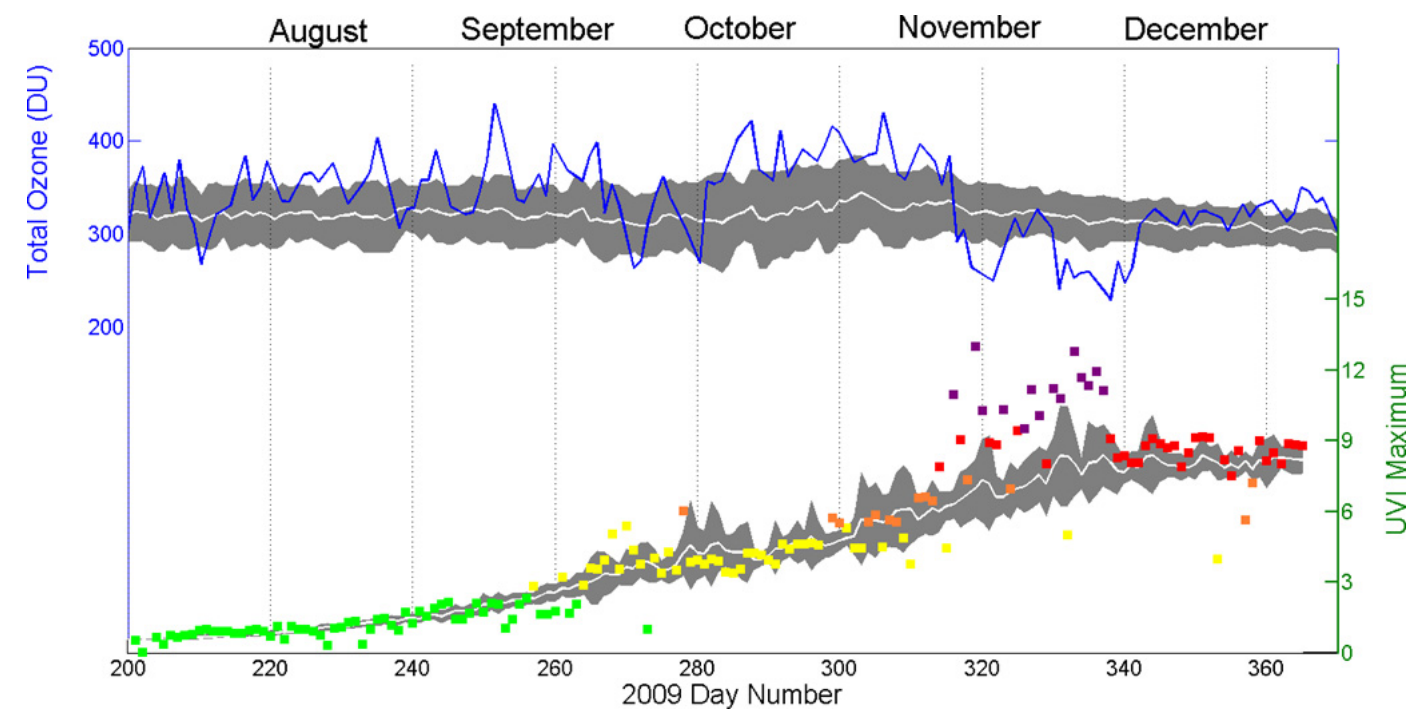

Fig. 6. Temporal evolution of daily maximum UV index (UVI) at ground surface for CEILAP-RG site (colored squares, lower panel, right axis). White line is the climatological daily mean of UVI (see text for explanation) and shadow area corresponds to \pm 1 SD. Temporal evolution of total ozone for Río Gallegos site (blue line, upper panel) with the climatological daily mean of total ozone (white line, upper panel). Shadow area corresponds to $\pm 1 \mathrm{SD}$.
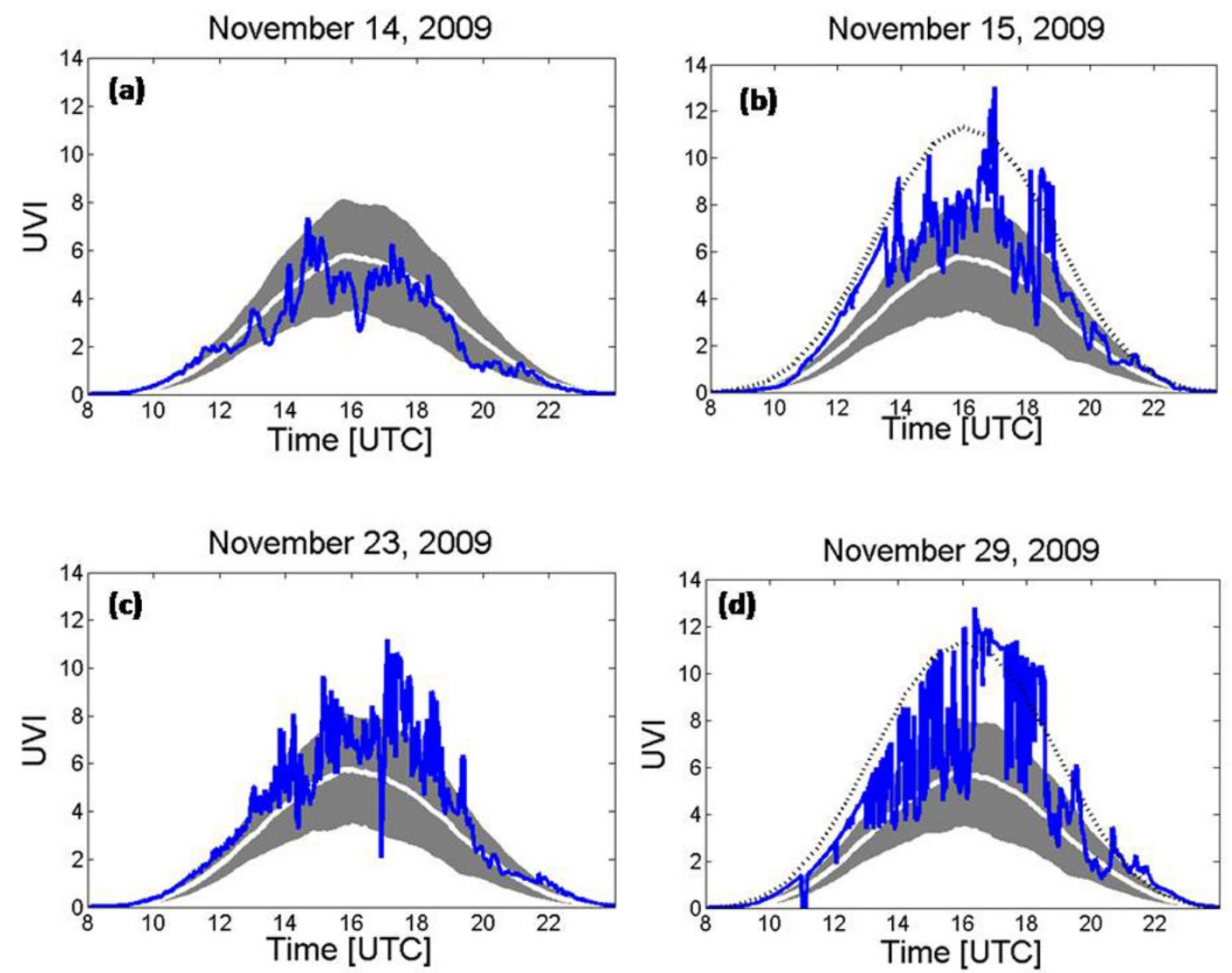

Fig. 7. Time evolution of UV index at Río Gallegos. The measurements were obtained with a GUV 541 for 14 November (a), 15 November (b), 23 November (c) and 29 November (d) and are plotted as blue lines. November monthly mean of UVI is shown as a white line and the shadow grey area corresponds to \pm 1 SD. Modeled UVI for 15 and 29 November are shown as dotted black lines. 

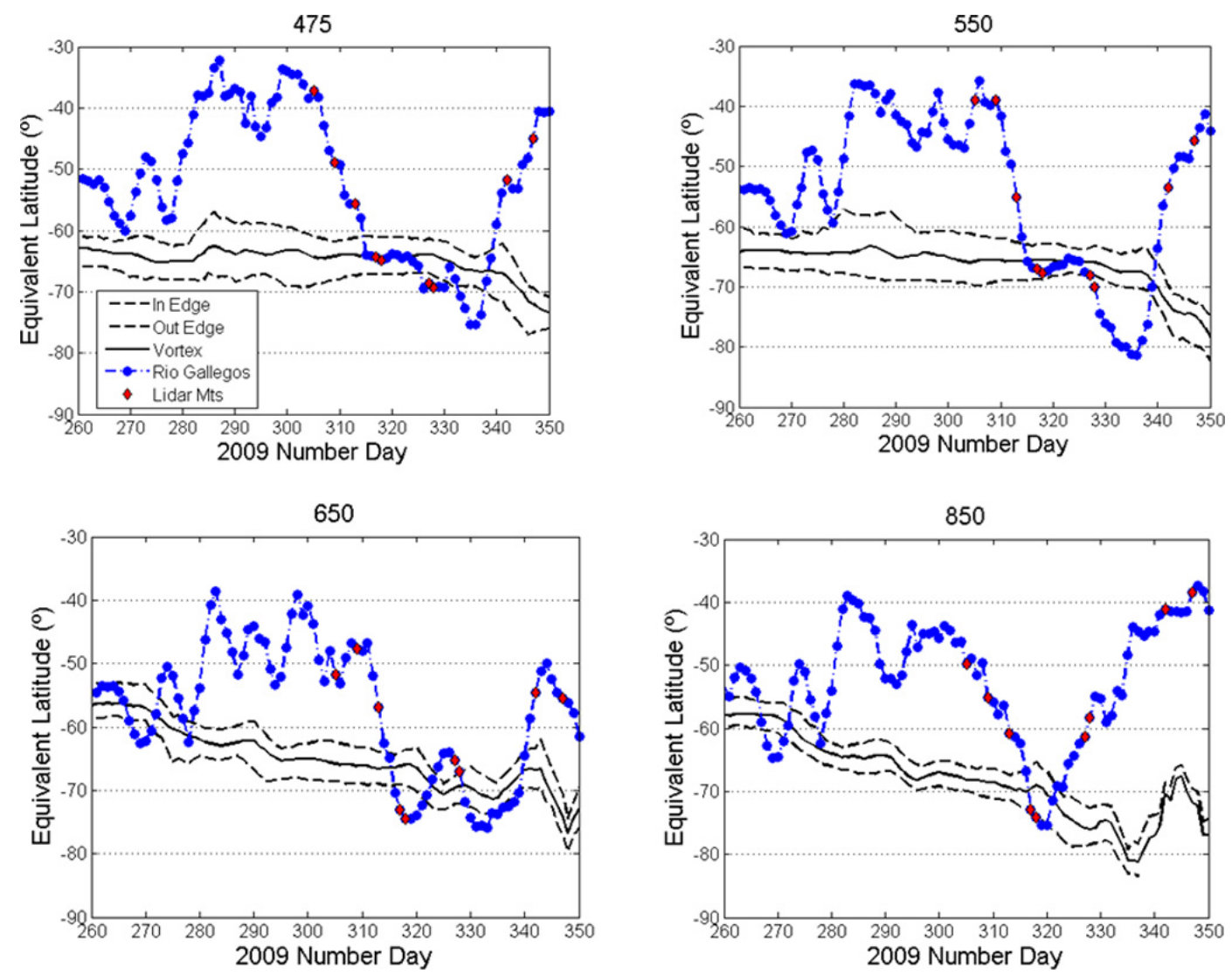

Fig. 8. Temporal evolution of equivalent latitude for the vortex limit positions (black line), inner and outer vortex edge (dashed lines), named as "In Edge" an "Out Edge", respectively, and the Río Gallegos station (blue circles) at four isentropic levels (475, 550, 650 and 850 K). Red diamonds indicate the lidar measurements considered in this study.

Table 4. Classification of lidar measurements with respect to vortex position at different isentropic levels.

\begin{tabular}{ccccccc}
\hline $\begin{array}{c}\text { Measurement } \\
\text { number }\end{array}$ & $\begin{array}{c}\text { Date } \\
\text { dd/mm/yyyy }\end{array}$ & Day number & $475 \mathrm{~K}$ & $550 \mathrm{~K}$ & $650 \mathrm{~K}$ & $850 \mathrm{~K}$ \\
\hline 1 & $01 / 11 / 2009$ & 305 & Out & Out & Out & Out \\
2 & $05 / 11 / 2009$ & 309 & Out & Out & Out & Out \\
3 & $09 / 11 / 2009$ & 313 & Out & Out & Out & Out \\
4 & $13 / 11 / 2009$ & 317 & Edge & Edge & In & Edge \\
5 & $14 / 11 / 2009$ & 318 & Edge & Edge & In & Edge \\
6 & $23 / 11 / 2009$ & 327 & In & In & Out & Out \\
7 & $24 / 11 / 2009$ & 328 & In & In & Edge & Out \\
8 & $08 / 12 / 2009$ & 342 & Out & Out & Out & Out \\
9 & $13 / 12 / 2009$ & 347 & Out & Out & Out & Out \\
\hline
\end{tabular}

with a GUV moderated narrow band radiometer at a rate of one measurement per minute. High impact of cloud cover is observed in the daily evolution of UVI, producing, in general, attenuation of the radiation as on 14 November (Fig. 7a).

On 15 November, total ozone column for Río Gallegos reaches $225 \mathrm{DU}$, and the absolute maximum in UVI $(\mathrm{UVI}=13)$ was measured after local noon, contrary to what would be expected for clear skies. The clouds were blocking the sun light at noon but reinforced the UV radiation that reached the ground in the first hour of the afternoon. The UV increase in partially cloudy sky is a phenomenon that has been documented by several researchers (Estupiñán et al., 1996; Crawford et al., 1999). Clouds with vertical development are the most effective in increasing UV radiation beyond the clear-sky limit. This enhancement occurs when the solar beam is unobstructed and additional radiation is scattered by clouds towards the ground. Estupiñan et al. (1996) found that these cumulus clouds can produce 
localized increases of UV-B radiation of up to $27 \%$ over timescales as long as one hour. Similar situations were found in the measurements analyzed here. Clear sky UV radiation levels were simulated with a TUV model V5.0 (Madronich, 1993) on 15 and 29 November, using as input parameters of the model the ozone total column corresponding to these days and monthly mean aerosol optical thickness from an AERONET sun photometer $(\mathrm{AOT}(500 \mathrm{~nm})=0.02)$. To validate the consistency of GUV measurements and results of the TUV model, measurements and model were compared for three almost cloud-free days in January and October 2009. The two quantities agreed to within $5-10 \%$, which is within their combined uncertainty. On 29 November, the ozone column was a little higher compared to 15 November, but the UVI levels were still higher during this day, and also higher than the model UVI for clear sky conditions as a consequence of cloud border enhancement after local noon.

\section{Discussion}

The circulation of the polar winter stratosphere is dominated by a large cyclonic vortex centered near the winter pole. The changes in the shape or location of this polar vortex are mainly responsible for the change in the stratospheric circulation. The time evolution position of Río Gallegos on equivalent latitude coordinate (hereafter RG-EqLat) shows that the station was outside the polar vortex at all isentropic levels considered in this study $(475,550,650$ and $850 \mathrm{~K})$ during the first 10 days of November (Fig. 8). This is reflected in the three first lidar measurements analyzed here (1, 4 and 9 November), which indicate ozone concentrations above the climatological mean at low altitudes due to the isentropic transport of ozone rich air-masses from mid-latitude lower stratosphere (Figs. 3 and 4). On the contrary, the RG-EqLat on 13 and 14 November show that Río Gallegos was located at the edge of the polar vortex in the lower stratosphere. In the upper levels of stratosphere $(650 \mathrm{~K}$ and $850 \mathrm{~K}$ isentropic level), the station was inside the polar vortex, especially at $650 \mathrm{~K}$ isentropic level (aprox. $24 \mathrm{~km}$ ) where the RG-EqLat was poleward the vortex position (see Table 4). This confirms that the polar vortex passed over Río Gallegos during the lidar measurements, and this is the reason for the observed ozone loss on 13 and 14 November (day number 317 and 318 , respectively). The situation was different on 23 and 24 November (day number 327 and 328), during which the station was inside the vortex at isentropic levels 475 and $550 \mathrm{~K}$ and outside the vortex at $675 \mathrm{~K}$. In the upper level $(850 \mathrm{~K})$, the station was fully outside during these two consecutive days. This situation explains the observed shapes of lidar profiles on these days that show reduction with respect to the climatological profile only below $28 \mathrm{~km}$ (Fig. 3). On the other hand, the lidar measurements on 8 and 13 December are similar to the climatological profiles as the observations were performed outside the vortex. A rapid recovery of the $\mathrm{O}_{3}$ column density was observed later due to an $\mathrm{O}_{3}$ rich filament moving over Río Gallegos between 18 and $24 \mathrm{~km}$, while simultaneously the $\mathrm{O}_{3}$ poor air moved away for the first two weeks of December 2009.

We have used the MIMOSA-CHIM CTM to evaluate the chemical ozone loss corresponding to the measurements performed at Río Gallegos. For this purpose, the passive ozone tracer (ozone calculated without interactive chemistry) simulated by MIMOSA-CHIM for lidar measurements for days in November is used. The chemical ozone loss is computed from the difference between the simulated tracer and the ozone mixing ratio evaluated from the lidar measurements. That is, the observed ozone loss in absolute units (ppmv) is estimated as lidar-tracer for each isentropic level. The ozone loss estimated on 13,14 and 24 November shows high ozone depletion in the $350-675 \mathrm{~K}$ range of about -2 ppmv on average (Fig. 9). This loss is due to halogen catalytic destruction cycles, which dominate chemical ozone loss processes within the polar vortex in the lower stratosphere during that period (Solomon, 1999). The model reproduces quite well the ozone behavior during the period, however the differences between model and lidar measurements do increase above the $650 \mathrm{~K}$ level. This may be because the model loses accuracy at higher levels in the stratosphere, and the effect of the modeled ozone profiles were interpolated to Río Gallegos. Figure 10 shows the model output of ozone concentration at the $500 \mathrm{~K}$ isenstropic level on 14 and 24 November 2009. The simulation confirms the fact that Río Gallegos was inside the polar vortex at this level during these days. The shape of the polar vortex appears more elongated on 14 November than 24 November, but on both days ozone poor air was over the Río Gallegos site.

\section{Conclusion}

An extremely persistent ozone hole overpass was observed from ground-based instruments at Río Gallegos in November 2009. This was the first time that an extreme event of this duration was observed from the ground at a subpolar station with a lidar instrument. Record-low ozone $\left(\mathrm{O}_{3}\right)$ column densities (with a minimum of $212 \mathrm{DU}$ ) persisted over three weeks at the Río Gallegos NDACC station in November 2009. The statistical analysis of 30 years of satellite data from the Multi Sensor Reanalysis (MSR) database for Río Gallegos revealed that such a long-lasting, low-ozone episode is a rare occurrence. This statistical analysis reveals that $3 \%$ of events only correspond to 4 or more consecutive days with total ozone column below two standard deviations of the daily climatological mean.

This event was examined using height-resolved $\mathrm{O}_{3}$ lidar measurements over Río Gallegos, and outputs of satellite and different ground-based instruments operational at the site. The computed relative difference between the measured total ozone and the climatological monthly mean shows 


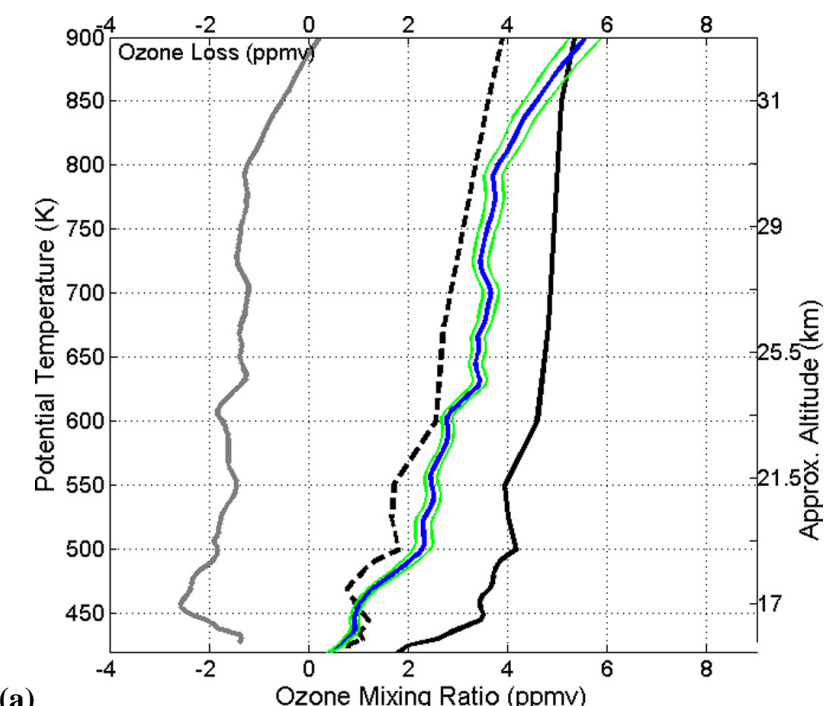

(a)

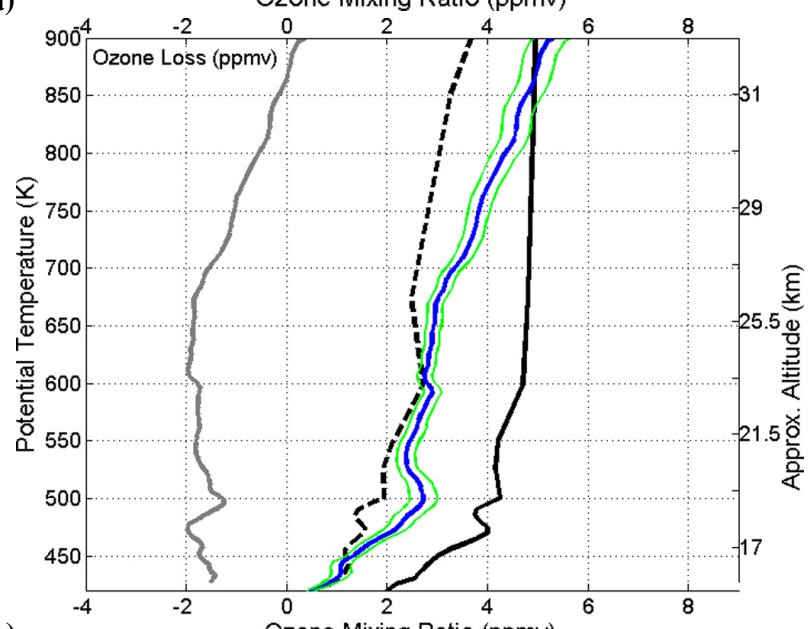

(b)

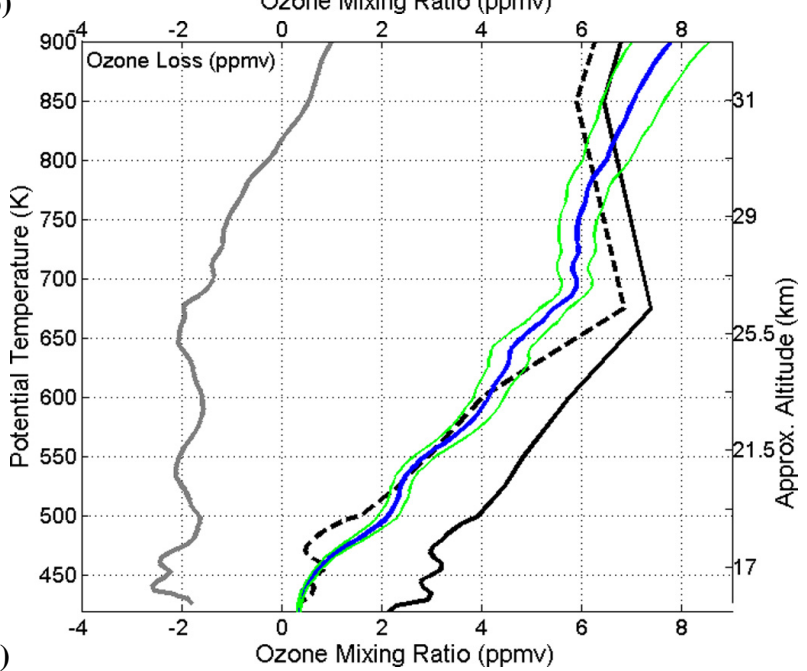

(c)

Fig. 9. Volume mixing ratio ozone profile measured by lidar (solid blue line) \pm lidar error (solid green line) and calculated by MIMOSA-CHIM (black dashed line). Passive ozone profile is plotted as a black solid line. Ozone loss is calculated as lidarpassive ozone (gray solid line). (a) corresponds to 13 November, (b) 14 November, and (c) 23 November. reductions varying between 10 and $30 \%$ with an average decrease of $25 \%$. The mean absolute difference of total ozone column with respect to climatological monthly mean ozone column was 62.2 DU for this 20-day period and 32.9 DU for the complete month of November. These ozone reductions cause higher levels of UV radiation at the ground. Extreme values of UV index were measured for this period of time, with daily maximum UVI of around 13 on 15 and 28 November. The cloud cover present on these days produced a strong modulation of UV radiation at the ground, resulting not only in UV reduction but also in enhancement beyond the values calculated for clear-skies with a radiative transfer model. This happens because cloud border reflections strengthen the UV radiation that reaches the radiometer at ground level. This shows how the combination of low ozone events and partially cloudy skies can result in dangerous events for humans, and this reinforces the necessity of having continuous monitoring programs of this type of event for public alert of dangerous UVI.

The position of Río Gallegos relative to the polar vortex was classified using a 2-D quasi-conservative coordinate system (equivalent latitude/potential temperature). The time evolution of Río Gallegos position in equivalent latitude shows that the station was outside the polar vortex at all isentropic level considered in this study $(475,550,650$ and $850 \mathrm{~K}$ ) during the first 10 days of November. Unlike this situation, the RG-EqLat on 13 and 14 November shows that Río Gallegos was located on the edge of the polar vortex in the lower stratosphere and inside the vortex in the middle stratosphere $(650 \mathrm{~K}$ and $850 \mathrm{~K}$ isentropic levels). The situation that occurred on 23 and 24 November was different. Only the lower stratospheric levels at $475 \mathrm{~K}$ and $550 \mathrm{~K}$ were inside the polar vortex, while at $650 \mathrm{~K}$ isentropic level the Río Gallegos station was outside the vortex, near the outer edge. A rapid recovery of the ozone column density was observed later due to an ozone rich filament moving over Río Gallegos between 18 and $24 \mathrm{~km}$, while simultaneously the ozone poor air moved away for the first two weeks of December 2009.

Consistent with the reduction of ozone observed by SAOZ, Brewer and satellite instruments, the ozone loss estimated from the lidar ozone measurements using the MIMOSACHIM model CTM during 13, 14 and 23 November also show high depletion of ozone in 350-675 K of about 2 ppmv, on average. This implies that the vortex overpasses at Río Gallegos in November 2009 were a unique event of great importance, as far as the ozone loss in the southern midlatitudes is concerned.

Beyond the significance and importance that this type of event had, this paper also shows the observational instrumental capabilities that the CEILAP-RG site has. This will be very relevant in the future for atmospheric studies, because the number of highly qualified ground-based stations with great diversity of instruments is very sparse is the Southern Hemisphere. 

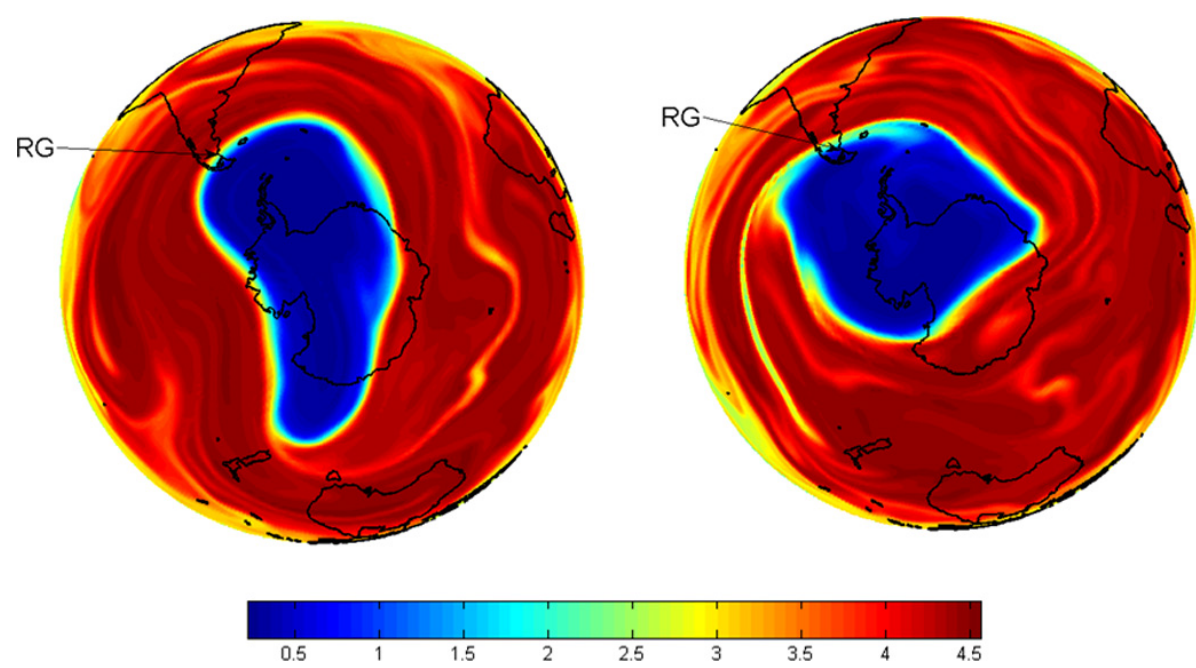

Fig. 10. Polar orthographic projection of ozone volume mixing ratio (in ppmv) at $500 \mathrm{~K}$ calculated by MIMOSA-CHIM. Left side corresponds to 13 November and rigth side corresponds to 24 November at 12:00 UTC. Río Gallegos position is indicated with the RG arrow.

Acknowledgements. The authors would like to thank JICA (Japan International Cooperation Agency) for their financial support; the CNRS in France for their collaboration in facilitating the shelter and part of the electronic instruments; to TEMIS group for the MSR database; to Project ATAMANTAR/PROANTAR/CNPq and INCTAPA/MCTI that supports Brewer calibration and transport to Argentina. Also thanks to the anonymous reviewers that have provided very useful comments, and have helped to improve the manuscript in a very substantial way.

Topical Editor C. Jacobi thanks O. Tripathi and one anonymous referee for their help in evaluating this paper.

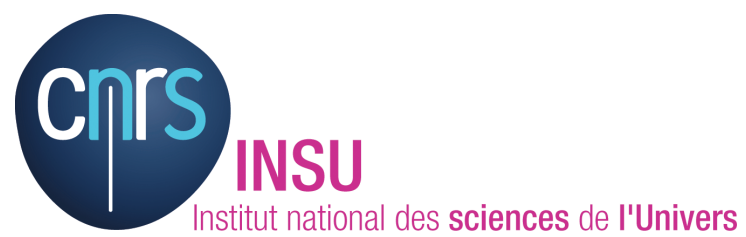

The publication of this article is financed by CNRS-INSU.

\section{References}

Austin, J., Scinocca, J., Plummer, D., Oman, L., Waugh, D. Akiyoshi, H., Bekki, S., Braesicke, P., Butchart, N., Chipperfield, M., Cugnet, D., Dameris, M., Dhomse, S., Eyring, V., Frith, S., Garcia, R. R., Garny, H., Gettelman, A., Hardiman, S. C., Kinnison, D., Lamarque, J. F., Mancini, E., Marchand, M., Michou, M., Morgenstern, O., Nakamura, T., Pawson, S., Pitari, G., Pyle, J., Rozanov, E., Shepherd, T. G., Shibata, K., Teyssèdre, H., Wilson, R. J., and Yamashita, Y.: Decline and recovery of total column ozone using a multimodel time series analysis, J. Geophys. Res., 115, D00M10, doi:10.1029/2010JD013857, 2010.

Booth, C. R. and Madronich, S.: Radiation Amplification Factors: Improved formulation accounts for large increases in ultraviolet radiation associated with Antarctic ozone depletion, Ultraviolet Radiation in Antarctica: Measurements and Biological Effects,
Antarctic Research Series, vol. 62, Amer. Geophys. Union, 3942, 1994.

Booth, C. R., Mestechkina, T., and Morrow, J. H.: Errors in the reporting of solar spectral irradiance using moderate bandwidth radiometers: an experimental investigation, in: Ocean Optics XII, SPIE, 2258, 654-663, 1994.

Brewer, A. W.: A replacement for the dobson spectrophotometer?, Pure Appl. Geophys., 919, 106-108, 1973.

Committee on Space Research (COSPAR): The COSPAR International Reference Atmosphere (CIRA-86), [Internet]. British Atmospheric Data Centre, available at: http://badc.nerc.ac.uk/data/ cira/, 2006.

Crawford, J., Davis, D., Chen, G., Shetter, R., Müller, M., Barrick, J., and Olson, J.: An assessment of cloud effects on photolysis rate coefficients: Comparison of experimental and theoretical values, J. Geophys. Res., 104, 5725-5734, 1999.

Dahlback, A.: Measurements of biologically effective UV doses, total ozone abundances, and cloud effects with multichannel, moderate bandwidth filter instruments, Appl. Optics, 35, 6514-6521, 1996.

de Laat, A. T. J., van der A, R. J., Allaart, M. A. F., van Weele, M., Benitez, G. C., Casiccia, C., Paes Leme, N. M., Quel, E., Salvador, J., and Wolfram, E.: Extreme sunbathing: Three weeks of small total $\mathrm{O}_{3}$ columns and high UV radiation over the southern tip of South America during the 2009 Antarctic $\mathrm{O}_{3}$ hole season, Geophys. Res. Lett., 37, L14805, doi:10.1029/2010GL043699, 2010.

Estupiñán, J. G., Raman, S., Crescenti, G. H., Streicher, J. J., and Barnard, W. F.: Effects of clouds and haze on UV-B radiation, J. Geophys. Res., 101, 16807-16816, 1996.

Eyring, V., Cionni, I., Bodeker, G. E., Charlton-Perez, A. J., Kinnison, D. E., Scinocca, J. F., Waugh, D. W., Akiyoshi, H., Bekki, S., Chipperfield, M. P., Dameris, M., Dhomse, S., Frith, S. M., Garny, H., Gettelman, A., Kubin, A., Langematz, U., Mancini, E., Marchand, M., Nakamura, T., Oman, L. D., Pawson, S., Pitari, G., Plummer, D. A., Rozanov, E., Shepherd, T. G., Shibata, K., Tian, W., Braesicke, P., Hardiman, S. C., Lamarque, J. F., Mor- 
genstern, O., Pyle, J. A., Smale, D., and Yamashita, Y.: Multimodel assessment of stratospheric ozone return dates and ozone recovery in CCMVal-2 models, Atmos. Chem. Phys., 10, 94519472, doi:10.5194/acp-10-9451-2010, 2010.

Feng, W., Chipperfield, M. P., Davies, S., Sen, B., Toon, G., Blavier, J. F., Webster, C. R., Volk, C. M., Ulanovsky, A., Ravegnani, F., von der Gathen, P., Jost, H., Richard, E. C., and Claude, H.: Three-dimensional model study of the Arctic ozone loss in 2002/2003 and comparison with 1999/2000 and 2003/2004, Atmos. Chem. Phys., 5, 139-152, doi:10.5194/acp-5-139-2005, 2005.

Fortuin, J. P. F. and Kelder, H.: An ozone climatology base on ozonesonde and satellite measurements, J. Geophys. Res., 103, 31709-31734, 1998.

Fuenzalida, H. A.: Global ultraviolet spectra derived directly from observations with multi-channel radiometers, Appl. Optics, 37, 7912-7919, 1998.

Global Solar UV Index: A Practical Guide World Health Organisation (WHO), World Meteorological organisation (WMO), United Nations Environment Program (UNEP), and International Commission on Non-Ionising Radiation Protection (ICNRP) (Geneva), 2002.

Godin, S., Bergeret, V., Bekki, S., David, C., and Mégie, G.: Study of the interannual ozone loss and the permeability of the Antarctic Polar Vortex from long-term aerosol and ozone lidar measurements in Dumont d'Urville $\left(66.4^{\circ} \mathrm{S}, 140^{\circ} \mathrm{E}\right)$, J. Geophys. Res., 106, 1311-1330, 2001.

Godin-Beekmann, S., Porteneuve, J., and Garnier, A.: Systematic DIAL lidar monitoring of the stratospheric ozone vertical distribution at Observatoire de Haute-Provence $\left(43.92^{\circ} \mathrm{N}, 5.71^{\circ} \mathrm{E}\right), \mathrm{J}$. Environ. Monit., 5, 57-67, 2003.

Hauchecorne, A., Godin, S., Marchand, M., Heese, B., and Souprayen, C.: Estimation of the Transport of Chemical Constituents from the Polar Vortex to Middle Latitudes in the Lower Stratosphere using the High-Resolution Advection Model MIMOSA and Effective Diffusivity, J. Geophys. Res., 107, D20, doi:10.1029/2001JD000491, 2002.

Hendrick, F., Pommereau, J.-P., Goutail, F., Evans, R. D., Ionov, D., Pazmino, A., Kyrö, E., Held, G., Eriksen, P., Dorokhov, V., Gil, M., and Van Roozendael, M.: NDACC/SAOZ UV-visible total ozone measurements: improved retrieval and comparison with correlative ground-based and satellite observations, Atmos. Chem. Phys., 11, 5975-5995, doi:10.5194/acp-11-5975-2011, 2011.

Kuttippurath, J., Godin-Beekmann, S., Lefèvre, F., and Goutail, F.: Spatial, temporal, and vertical variability of polar stratospheric ozone loss in the Arctic winters 2004/2005-2009/2010, Atmos. Chem. Phys., 10, 9915-9930, doi:10.5194/acp-10-9915-2010, 2010a.

Kuttippurath, J., Goutail, F., Pommereau, J.-P., Lefèvre, F., Roscoe, H. K., Pazmiño, A., Feng, W., Chipperfield, M. P., and GodinBeekmann, S.: Estimation of Antarctic ozone loss from groundbased total column measurements, Atmos. Chem. Phys., 10, 6569-6581, doi:10.5194/acp-10-6569-2010, 2010b.

Lee, A. M., Roscoe, H. K., Jones, A. E., Haynes, P. H., Shuckburgh, E. F., Morrey, M. W., and Pumphrey, H. C.: The impact of the mixing properties within the Antarctic stratospheric vortex on ozone loss in spring, J. Geophys. Res., 106, 3203-3211, 2001.
Lefèvre, F., Brasseur, G. P., Folkins, I., Smith, A. K., and Simon, P.: Chemistry of the 1991-1992 stratospheric winter: Threedimensional model simulations, J. Geophys. Res., 99, 81838195, 1994.

Levelt, P. F., van den Oord, G. H. J., Dobber, M. R., Mlkki, A., Visser, H., de Vries, J., Stammes, P., Lundell, J., and Saari, H.: The Ozone Monitoring Instrument, IEEE T. Geosci. Remote Sens., 44, 1093-1101, 2006.

Madronich, S.: UV radiation in the natural and perturbed atmosphere, in: Environmental Effects of UV (Ultraviolet) Radiation,, edited by: Tevini, M., Lewis Publisher, Baca Raton, pp. 17-69. TUV model, web page: http://www.acd.ucar.edu/TUV/, 1993.

McIntyre, M. and Palmer, T.: The 'surf zone' in the stratosphere, J. Atmos. Terr. Phys., 46, 825-849, 1984.

Nash, E. R., Newman, P. A., Rosenfield, J. E., and Schoeberl, M. E.: An objective determination of the polar vortex using Ertel's potential vorticity, J. Geophys. Res., 101, 9471-9478, 1996.

Newman, P. A., Kawa, S. R., and Nash, E. R.: On the size of the Antarctic ozone hole, Geophys. Res. Lett., 31, L21104, doi:10.1029/2004GL020596, 2004.

Newman, P. A., Nash, E. R., Kawa, S. R., Montzka, S. A., and Schauffler, S. M.: When will the Antarctic ozone hole recover?, Geophys. Res. Lett., 33, L12814, doi:10.1029/2005GL025232, 2006.

Orce, V., Helbling, E., Paladini, A., Labraga, J., Sanroman, N., and Paladini, A. A.: Latitudinal Uvr-par Measurements in Argentina - Extent of the Ozone Hole (Vol 15, Pg 113, 1997), Global Planet. Change, 18, 75-75, 1998.

Pazmiño, P. A., Wolfram, E., Quel, E., Lavorato, M., Piacentini, R., Godin, S., Porteneuve, J., and Mégie, G.: Intercomparison Of Ozone Profiles Measurements By A Differential Absorption Lidar System And Satellites At Buenos Aires, Argentina, Proceedings del SPIE, Vol. 4419, ISSN 0277-786X/ISBN 0-81944126-0, pp. 499-502, 2001.

Pazmiño, A., Godin-Beekmann, S., Ginzburg, M., Bekki, S., Hauchecorne, A., Piacentini, R., and Quel, E.: Impact of Antartic polar vortex occurrences on total ozone and UVB radiation at southern Argentinean and Antarctic stations during 1997-2003 period, J. Geophys. Res., 110, D03103, doi:10.1029/2004JD005304, 2005.

Pommereau, J. P. and Goutail, F.: Stratospheric $\mathrm{O}_{3}$ and $\mathrm{NO}_{2}$ observations at the southern polar circle in summer and fall 1988, Geophys. Res. Lett., 15, 895-897, doi:10.1029/GL015i008p00895, 1988.

Roscoe, H. K., Johnston, P. V., Van Roozendael, M., Richter, A., Preston, K., Lambert, J. C., Hermans, C., de Cuyper, W., Dzenius, S., Winterath, T., Burrows, J., Sarkissian, A., Goutail, F., Pommereau, J. P., d'Almeida, E., Hottier, J., Coureul, C., Ramond, D., Pundt, I., Bartlet, L. M., Kerr, J. E., Elokhov, A., Giovanelli, G., Ravegnani, F., Premudan, M., Kostadinov, M., Erle, F., Wagner, T., Pfeilsticker, K., Kenntner, M., Marquand, L. C., Gil, M., Puentedura, O., Arlander, W., Kastad-Hoiskar, B. A., Tellefsen, C. W., Heese, C. W., Jones, R. L., Aliwalle, S. R., and Freswater, R. A.: Slant column measurements of $\mathrm{O}_{3}$ and $\mathrm{NO}_{2}$ during the NDSC intercomparison of zenith-sky UVvisible spectrometers in June 1996, J. Atmos. Chem., 32, 281314, 1999.

Roscoe, H. K., Shanklin, J. D., and Colwell, S. R.: Has the Antarctic Vortex Split before 2002?, J. Atmos. Sci., 62, 581-588, 
doi:10.1175/JAS-3331.1, 2005.

Solomon, S.: Stratospheric ozone depletion: A review of concepts and history, Rev. Geophys., 37, 275-316, doi:10.1029/1999RG900008, 1999.

Tripathi, O. P., Godin-Beekmann, S., Lefèvre, F., Marchand, M., Pazmiño, A., Hauchecorne, A., Goutail, F., Schlager, H., Volk, C. M., Johnson, B., König-Langlo, G., Balestri, S., Stroh, F., Bui, T. P., Jost, H. J., Deshler, T., and von der Gathen, P.: High resolution simulation of recent Arctic and Antarctic stratospheric chemical ozone loss compared to observations, J. Atmos. Chem., 55, 205226, doi:10.1007/s10874-006-9028-8, 2006.

van der A, R. J., Allaart, M. A. F., and Eskes, H. J.: Multi sensor reanalysis of total ozone, Atmos. Chem. Phys. Discuss., 10, 11401-11448, doi:10.5194/acpd-10-11401-2010, 2010.

Vaughan, G., Roscoe, H. K., Bartlett, L. M., O'Connor, F. M., Sarkissian, A., Van Roozendael, M., Lambert, J.-C., Simon, P. C., Karlsen, K., Kaastad Hoiskar, B. A., Fish, D. J., Jones, R. L., Freshwater, R., Pommereau, J.-P., Goutail, F., Andersen, S. B., Drew, D. G., Hughes, P. A., Moore, D., Mellqvist, J., Hegels, E., Klupfel, T., Erle, F., Pfeilsticker, K., and Platt, U.: An intercomparison of ground-based UV- visible sensors of Ozone and NO2, J. Geophys. Res., 102, 1411-1422, 1997.
Wolfram, E. A., Salvador, J., Pallotta, J., D’Elia, R., Otero, L., Godin-Beeckmann, S., Nakane, H., and Quel, E.: Solar Campaign: First Results Of Ozone Profile Measurements At Rio Gallegos, Argentina, in: Reviewed and Revised Papers Presented at the 23rd International Laser Radar Conference, edited by: Nagasawa, C. and Sugimoto, N., ISBN 4-9902916-0-3, Part II, 365368, 2006.

Wolfram, E. A., Salvador, J., D'Elia, R., Casiccia, C., Paes Leme, N., Pazmiño, A., Porteneuve, J., Godin-Beekmann, S., Nakane, H., and Quel, E.: New differential absorption lidar for stratospheric ozone monitoring in Patagonia, South Argentina, J. Opt. A: Pure Appl. Opt., 10, 104021, doi:10.1088/14644258/10/10/104021, 2008.

World Meteorological Organization (WMO): Scientific assessment of ozone depletion: 2006, in Global Ozone: Past and Present, Global Ozone Res. Monit. Proj. Rep. 50, World Meteorol. Organ., Geneva, Switzerland, 2007.

World Meteorological Organization (WMO): Scientific Assessment of Ozone Depletion: 2010, Global Ozone Research and Monitoring Project-Report No. 52, 516 pp., Geneva, Switzerland, 2011.

Yang, E.-S., Cunnold, D. M., Newchurch, M. J., and Salawitch, R. J.: Change in ozone trends at southern high latitudes, Geophys. Res. Lett., 32, L12812, doi:10.1029/2004GL022296, 2005. 